\title{
Laboratory Simulation of Waves in an Ice Floe
}

\author{
A. O. OFUYA \\ Department of Civil Engineering, Queen's University \\ Kingston, Canada \\ A. J. REYNoLDS \\ Department of Civil Engineering and Applied Mechanics \\ McGill University, Montreal, Canada
}

\begin{abstract}
An attempt is made to determine whether the complex natural phenomenon of the interaction of pack ice and ocean waves can be studied effectively in a laboratory model. Owing to the large number of variables involved in such a study, this paper considers mainly the relatively easier problem of the study of the dynamic behavior of ocean waves and an ice floe. Ocean waves and ice floes are simulated by waves in a laboratory channel and by thin floating sheets of polyethylene. From theoretical considerations, the phase velocity of waves through the sheet and the factors that influence wave reflection and transmission are developed. Phase velocity can be expressed as a function of the effective modulus of elasticity, density and thickness of polyethylene, the density of water, and the velocity of waves on a free water surface. Reflection and transmission depend on a number of dimensionless parameters, such as the ratio of sheet thickness to the incident wave height and the ratio of the elastic wave energy in the sheet to the incident gravitational wave energy. The reflection and transmission coefficients of the system and the phase velocity of waves propagating through the sheet are determined experimentally. A comparison of the theoretical predictions and results from model test indicates that a reasonable agreement exists between theory and experiment. Measurements of spectral energy density in open sea and results from model studies of this kind, which, however, take into account the patchiness of floes, may be applied to predict the attenuation experienced by waves that pass into pack ice. Values of effective viscosities determined from the simple model are applied to predict wave attenuation based on Robin's measurements in the south polar sea. The limitations of the model study are discussed.
\end{abstract}

\section{INTRODUCTION}

As an initial attempt in the laboratory study of the dynamic behavior of ocean waves and ice floes, this paper treats the following problems:

1. The experimental verification of the theoretical prediction of the phase velocity of waves propagating through a floating elastic plate.

2. The comparison of the experimental reflection, transmission characteristics of the thin plate with theory.

3. The study of the wave damping of the plate, with emphasis on the effect of the system on waves of short lengths and the application of the effective viscosities for this system to wave measurements made at sea.

The scientific literature on wave propagation through floating or semi-immersed bodies may be divided, for the purposes of this investigation, into the following categories: the response of floating bodies of various shapes to surface waves [John, 1949]; the effect of surface waves on ice floes [Weitz and Keller, 1953; Shapiro and Simpson, 1953]; wave propagation in elastic plates [Oliver et al., 1954; Hendrickson et al., 1962; Hendrickson and Webb, 1963; Reynolds, 1963, 1965a, b]; wave studies in the arctic ocean [Hunkins, 1962; Robin, 1963a; Le Schack, 1965]; and the unique experimental observations reported by Robin [1963b] of the behavior of ice floes and surface waves in the south polar sea.

\section{Notation}

$a$, amplitude of waves in the sheet (meters).

$a_{0}$, amplitude of incident waves (meters).

$b$, thickness of polyethylene, or ice floe (meters).

c, phase velocity in fluid (m/sec). 
$C$, phase velocity in plate-water system (m/sec).

$E$, modulus of elasticity of polyethylene or plate $\left(\mathrm{kg} / \mathrm{m}^{2}\right)$.

$E_{1}$, energy of incident waves.

$E_{4}$, energy of transmitted waves.

$f$, frequency of wave motion (cps).

$g$, acceleration due to gravity (980 $\left.\mathrm{cm} / \mathrm{sec}^{2}\right)$.

$h$, depth of water (meters).

$H_{i}$, amplitude of incident waves (meters).

$H_{r}$, amplitude of reflected waves (meters).

$H_{\text {l, }}$ amplitude of transmitted waves (meters).

$I$, moment of inertia of plate (meters 4 ).

$k, k_{1}$, wave numbers, $2 \pi / \lambda$.

$L_{t}$, length of plate or ice floe (meters).

$L$, characteristic wave amplitude decay length (meters).

$L_{0}$, characteristic wave amplitude decay length in an oil covered water surface (meters).

$L_{p}$, characteristic wave amplitude decay length in floating plate (meters).

$P_{2}, P_{a}, P_{a}, P_{w}$, pressures $\left(\mathrm{kg} / \mathrm{m}^{2}\right)$.

$s$, Reynolds number $\left(c / \gamma_{1} k\right)$.

$t$, time (sec).

$x$, distance from leading edge of sheet (meters).

$\alpha, 2 \pi b / \lambda_{\text {p* }}$

$\eta, \eta_{1}, \cdots, \eta_{4}$, amplitudes of waves above or below still water level (meters).

$\gamma$, Poisson's ratio.

$\gamma_{1}$, kinematic viscosity of fluid $\left(\mathrm{m}^{2} / \mathrm{sec}\right)$.

$\gamma_{w}$, kinematic viscosity of water ( $\left.\mathrm{m}^{2} / \mathrm{sec}\right)$.

$\mu$, dynamic viscosity of fluid (kg $\left.\mathrm{sec} / \mathrm{m}^{2}\right)$.

$\mu_{w}$, dynamic viscosity of water at $32^{\circ} \mathrm{F} \quad\left(1.793 \times 10^{-9}\right.$ dyne $\left.\mathrm{sec} / \mathrm{cm}^{2}\right)$.

$\lambda_{i}$, wavelength of incident waves (meters).

$\lambda_{p}$, wavelength of waves in plate (meters)

$\lambda$, wavelength (meters).
$\Phi_{2}, \Phi_{3}, \varphi_{3}, \varphi_{3}$, velocity potentials.

$\rho_{e}$, density of polyethylene $\left(\mathrm{kg} / \mathrm{m}^{\mathrm{s}}\right)$.

$\rho_{w}$, density of water $\left(\mathrm{kg} / \mathrm{m}^{3}\right)$.

$\sigma_{i}$, frequency (circular) of incident waves ( $\mathrm{rad} / \mathrm{sec})$.

\section{Theoretical Consmerations}

General. The theoretical phase velocity of wave propagation through an elastic plate is investigated by considering the dynamic response of a freely floating elastic plate, infinite in extent, to the pressure forces created by wave motion. The floating plate simulates an unbroken ice floe floating unrestrained in the sea or lake.

The rotational inertia and the shear deflections of the plate are neglected; hence the theory is applicable to waves of large lengths compared with plate thickness. The following assumptions and restrictions are made: (1) The fluid is incompressible and homogeneous. (2) The wave heights are small, and the thickness of the plate is small compared with its radius of curvature in its deflected form. (3) No fluid lies on top of the plate. (4) The motion of the fluid is irrotational. (5) The effective modulus of elasticity and the Poisson's ratio of the plate are constant. (6) In the frame of axes shown in Figure 1, the plate deforms to the geometrical shape $\eta=a \sin k x$.

It is assumed that the magnitude of the pressure differential across the sheet is sufficient to create the instantaneous force to deflect and accelerate the sheet. By applying Newton's second law of motion, taking into consideration the effect of gravity and the fact that the curvature of the sheet exists in one plane only, we have

$$
\begin{aligned}
P_{w} & -P_{\mathrm{c}} \\
& =\frac{E I}{1-\gamma^{2}} \frac{d^{4} \eta}{d x^{4}}+\rho_{\mathrm{s}} b\left(g+C^{2} \frac{d^{2} \eta}{d x^{2}}\right)
\end{aligned}
$$

The irrotational motion of the fluid is given by the perturbation potential

$$
\phi=-c a\left(\frac{e^{k y}}{1-e^{-2 k h}}+\frac{e^{-k y}}{e^{2 k h}-1}\right) \cos k x
$$

In the frame of reference moving with the wave crest, 


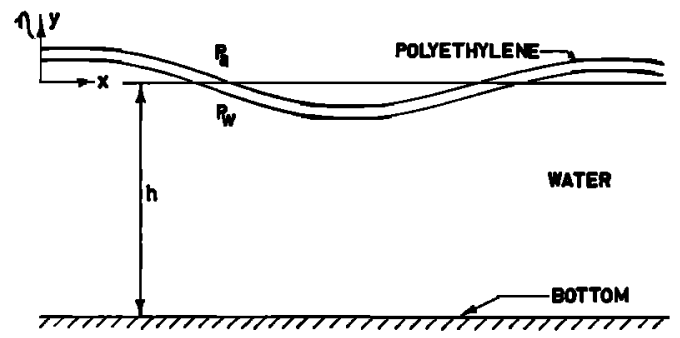

Fig. 1. Deflected shape of floating sheet.

$$
\begin{aligned}
& u=-C+\partial \phi / \partial x \\
& v=\partial \phi / \partial y
\end{aligned}
$$

Bernoulli's theorem is applied to the motion of the fluid following the lower surface of the plate, and the equation is linearized. The phase velocity of waves in the plate is found to be

$$
C^{2}=\left(C_{E}^{2}+B_{1} C_{w}^{2}\right) /\left(1+B_{1}\right)
$$

where

$$
\begin{aligned}
B_{1} & =\left(\rho_{w} \operatorname{coth} k h\right) / \alpha \rho_{s} \\
{C_{E}}^{2} & =E \alpha^{2} / 12 \rho_{a}\left(1-\gamma^{2}\right) \\
C_{w}{ }^{2} & =(g b / \alpha) \tanh k h
\end{aligned}
$$

and where $C_{s}$ and $C_{\infty}$ represent the phase velocities of flexural waves in a free plate and waves on a free water surface, respectively.

Wave reflection and transmission. The dimensionless factors influencing wave reflection and transmission can be found to be functions of the elastic properties of the plate, the incident wavelengths and wave heights, and plate thickness. For reflection, we have

$$
\frac{H_{r}}{H_{i}}=f_{1}\left(\frac{E b^{3}}{\rho_{w} g \lambda_{i}{ }^{4}}, \frac{\rho_{j}}{\rho_{v v}}, \frac{b}{H_{i}}\right)
$$

and for transmission

$$
\frac{H_{t}}{H_{i}}=f_{2}\left(\frac{E b^{3}}{\rho_{w} g \lambda_{i}{ }^{4}}, \frac{L_{p}}{L_{t}}, \frac{\rho_{s}}{\rho_{w}}, \frac{b}{H_{i}}\right)
$$

For reflection from, and transmission through, a broken ice field, the elastic properties can be neglected, and hence the factor $E b^{3} / \rho_{w} g \lambda_{i}{ }^{6}$ can be omitted from equations 3 and 4 .

\section{EXPERIMENT}

Equipment. The experimental wave channel, shown in Figure 2, is rectangular in cross section, with glass walls and a metal bottom. It is

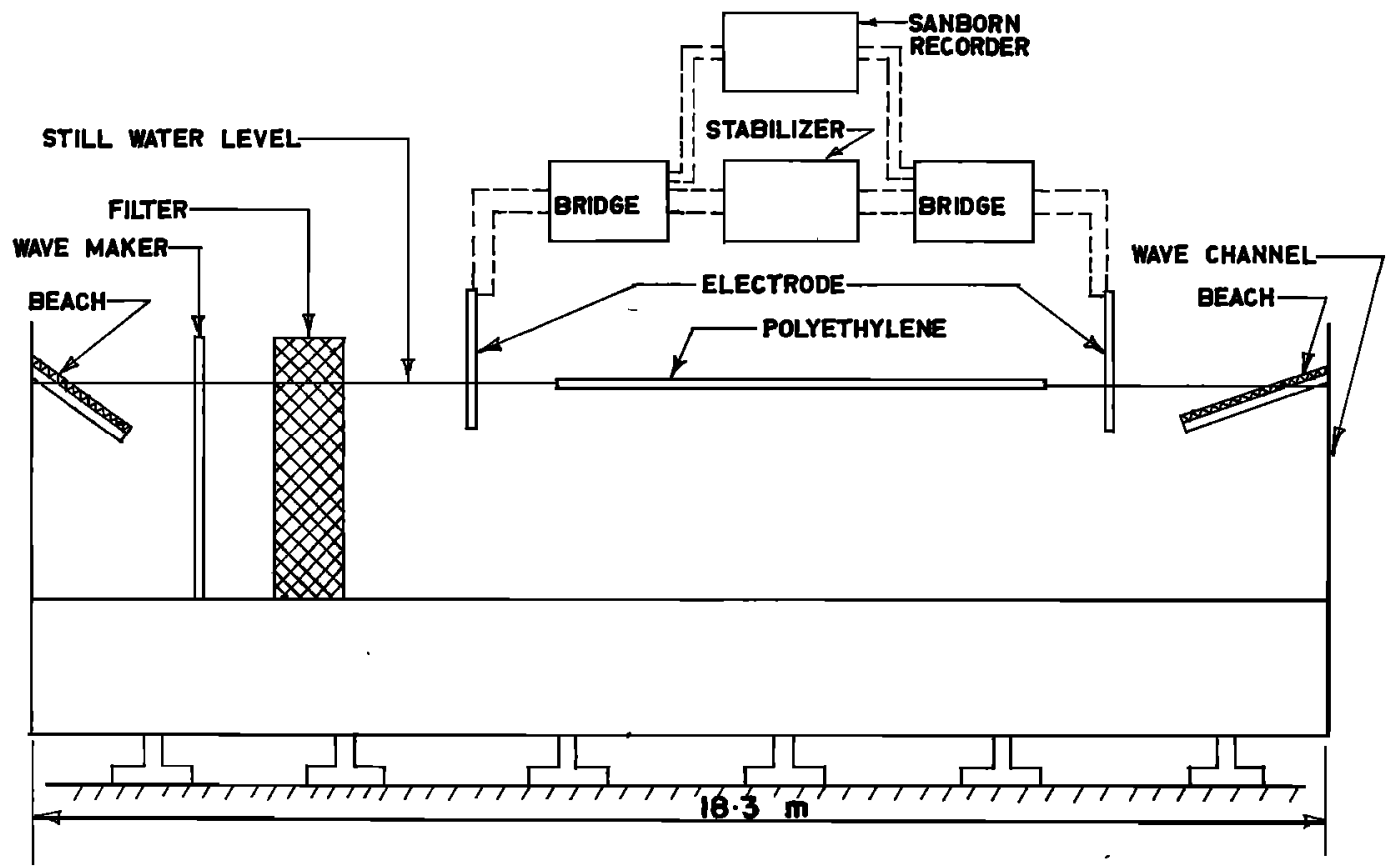

Fig. 2. Functional arrangement of equipment. 
18.3 meters long, 0.915 meter deep, and 0.92 meter wide and is supported 0.92 meter above the laboratory floor. Near one end of the channel is located a hinged-type wave maker with suitable adjustment for varying its pitch. There are mildly sloping beaches, one of which is fixed behind the wave maker and the other located at the other end of the channel, distant from the wave maker. An expanded aluminum metal filter, required to smooth the waves, is located 0.46 meter from the wave maker. The available space for experiment in the channel is approximately 11 meters between the filter and the beach. The electrical wave measuring equipment (R23 manufactured by Kempf and Remmers, Hamburg, Germany) comprises a voltage stabilizer, electrodes, and bridges.

The measurements of the beight of waves in the channel is made by measuring the changes in the voltage of the electrical elements composing the electrodes, which consist of two carbon plates, insulated from each other and attached onto the sides of a plastic rod about 0.45 meter long and $4.5 \mathrm{~cm}$ wide, of streamlined cross section, with a maximum thickness of about $0.48 \mathrm{~cm}$. Water waves pass the electrodes whose resistances are functions of their depths of submergence in water. The electrodes, placed vertically into the channel, are connected to a low ac voltage. With the electrodes partly immersed in water, the magnitude of the alternating current passing through the water from one carbon plate to the other is proportional to their depth of immersion, provided that they are located well away from a wall. Output from the electrodes passes through bridges, which consist of measuring circuits and compensating circuits, and is then amplified and recorded on perma paper by the Sanborn dual channel dc amplifier recorder (Model 320). (The electrode, a sample wave record, and the general arrangement of the electrical equipment are shown in Figures 3, 4, and 5.)

The electrodes are calibrated statically by varying their depths of submersion in water in the wave channel and observing the resulting deflection of the pens of the recorder. The constant obtained by static calibration is assumed to remain valid even when the water depth is fluctuating at about 4 cps or more, since small harmonic waves of frequency up to $12 \mathrm{cps}$ superposed on the basic waves are considerably damped by the filtering circuit. Since wave amplitudes are of the order of $\mathbf{1 0}$ $\mathrm{cm}$ and the resonant circuits filter out wave harmonics, the error introduced by the lag in the dynamic response due to the draining effect of water may be neglected. Hence, the recording of water waves may be evaluated on the basis of the static calibration.

The unbroken ice floe floating in water is simulated by thin sheets of polyethylene. In its high density form, polyethylene has a specific gravity of 0.95 to 0.96 and an effective modulus of elasticity in flexure varying from $1.15 \times 10^{4}$ to $1.54 \times 10^{4} \mathrm{~kg} / \mathrm{cm}^{2}\left(1.64 \times 10^{5}\right.$

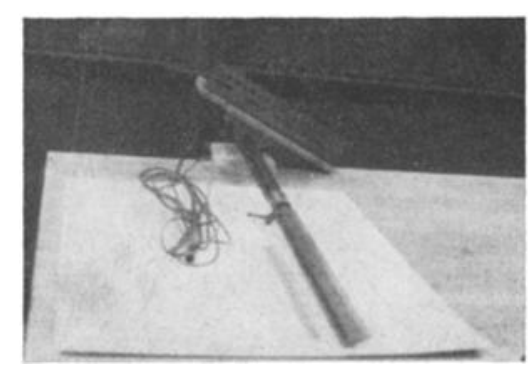

Fig. 3. Electrode.

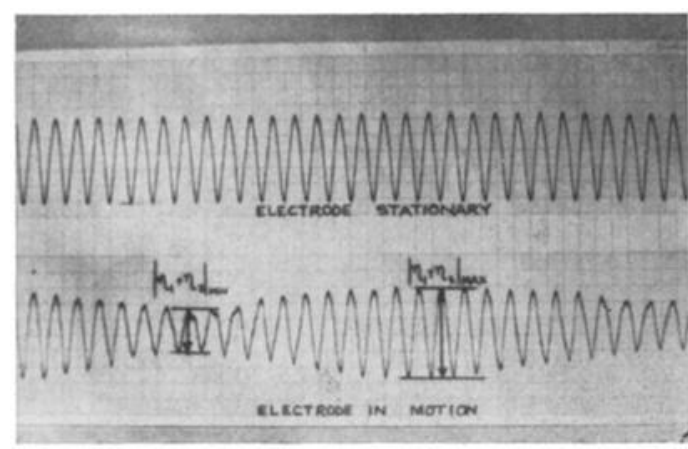

Fig. 4. A 'sample wave record.

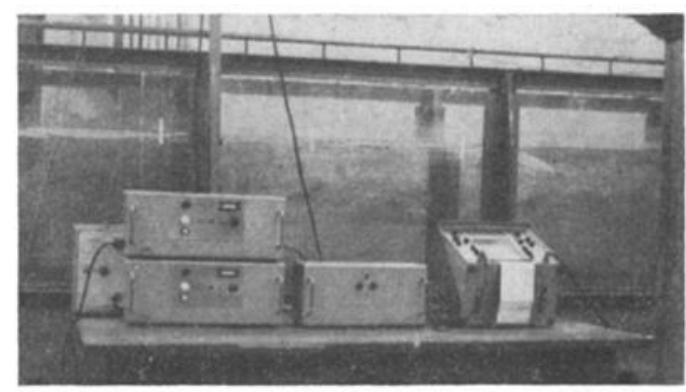

Fig. 5. General arrangement of the electrical equipment. 
The range of $\lambda_{i}$ is 0.61 to 4.56 meters.

TABLE 1

\begin{tabular}{|c|c|c|c|c|c|c|}
\hline Test & Model & $\begin{array}{c}\text { Thickness } \\
b, \mathrm{~cm}\end{array}$ & $\begin{array}{l}\text { Width } \\
W, \text { meter }\end{array}$ & $\begin{array}{c}\text { Length } \\
L_{\iota}, \text { meters }\end{array}$ & $\begin{array}{c}\text { Length of } \\
\text { Identation } \\
L_{1}, \text { meter }\end{array}$ & Type of Test \\
\hline 1 & 1 & 0.153 & 0.915 & 8.25 & 0 & Reflection and transmission \\
\hline 2 & 2 & 0.153 & 0.915 & 3.05 & 0 & Reflection and transmission \\
\hline 3 & 1 & 0.153 & 0.915 & 3.05 & 0 & Reflection and transmisaion \\
\hline 4 & 1 & 0.153 & 0.915 & 4.87 & 0.305 & Reflection and transmission \\
\hline $\mathbf{5}$ & 1 & 0.153 & 0.915 & 3.66 & 0.610 & Reflection and transmission \\
\hline 6 & 1 & 0.153 & 0.915 & 3.05 & 0.915 & Reflection and transmission \\
\hline 7 & 1 & 0.153 & 0.915 & 5.03 & 0 & $\begin{array}{l}\text { Attenuation, reflection, and } \\
\text { transmission }\end{array}$ \\
\hline 8 & 1 & 0.153 & 0.915 & 5.03 & 0.305 & Phase velocity \\
\hline 9 & 1 & 0.476 & 0.915 & 5.03 & 0 & Phase velocity and drift \\
\hline 10 & $\mathbf{1}$ & 0.476 & 0.915 & 6.1 & $\mathbf{0}$ & Drift \\
\hline
\end{tabular}

to $2.20 \times 10^{5} \mathrm{psi}$ ), depending on its thickness. Table 1 shows the dimensions of the sheets, the lengths of indentations, and the range of wavelengths used in the experiments.

Techniques. The ends of the floating sheet were connected to a number of strings loosely held in place in the channel to prevent longitudinal drift of the sheet during the passage of waves. An attempt to vary and improve the wave energy acceptance of the floating sheet resulted in the device of indenting its leading and trailing edges as shown in plan view in Figure 6 (top). From tests 3 to 6 , shown in Table 1, energy acceptance characteristics of the sheet under the various edge conditions were determined. Model 2, shown in elevation view in Figure 6 (bottom), was abandoned because of the effect of the large local $b / H_{t}$ at the leading edge. The interaction of the incident and reflected wave trains resulted in an irregular three-dimensional motion of waves in the channel.
The lengths of the generated waves were calculated by solving the equation [Lamb, 1932]

$$
\sigma_{i}^{2}=g k_{i} \tanh k_{i} h
$$

The frequencies of water waves and waves in the sheet were taken to be identical to those of the wave maker.

A constant depth of 0.61 meter of water in the channel was used for the investigation. The wavelengths in the sheet were calculated from the phase velocity and frequency measurements. Wavelengths of the incident waves and waves in the sheet are compared in Table 2. From the measurements of the deflections of the floating sheet, obtained by using scales attached to the sides of the channel, a characteristic decay length, $L_{p}$, of waves in the sheet is calculated. Wave heights of the incident waves are measured from the trace on the Sanborn recorder. From the wave height envelopes of the wave forms existing in the uncovered sec-

TABLE 2. Comparison of $\lambda_{i}$ and $\lambda_{p}$ at Same Frequency

\begin{tabular}{ccccc}
\hline $\begin{array}{c}\text { Frequency } \\
f, \text { cps }\end{array}$ & $\begin{array}{c}\text { Wavelength } \\
\lambda_{i} \text {, meters }\end{array}$ & $\begin{array}{c}\text { Phase Velocity } \\
\text { Experiment } \\
c_{p,} \text { m/sec }\end{array}$ & $\begin{array}{c}\text { Wavelength } \\
\lambda_{p} \text {, meters }\end{array}$ & $\lambda_{p} / \lambda_{i}$ \\
\hline 0.710 & 2.74 & 1.98 & 2.79 & 1.018 \\
0.770 & 2.44 & 1.93 & 2.5 & 1.025 \\
0.835 & 2.134 & 1.86 & 2.23 & 1.047 \\
0.910 & 1.83 & 1.82 & 2.0 & 1.093 \\
1.01 & 1.524 & 1.80 & 1.79 & 1.174 \\
1.12 & 1.22 & 1.83 & 1.63 & 1.337 \\
\hline
\end{tabular}




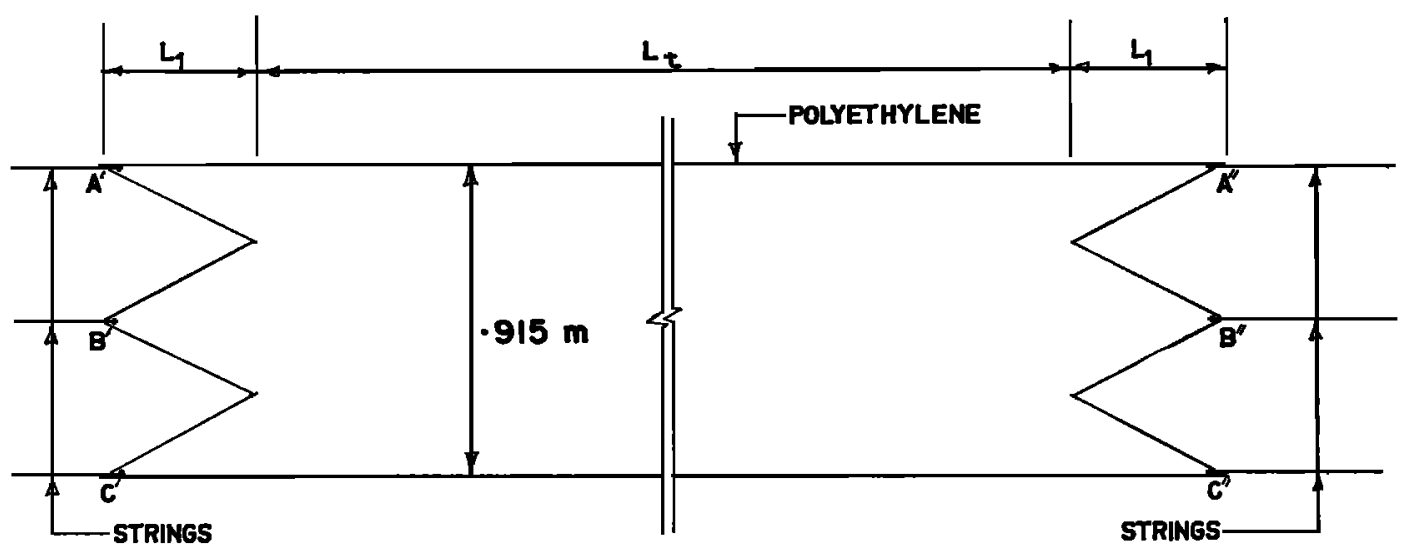

MODEL 1- PLAN YIEW

\section{MODEL 2 - ELEVATION}

Fig. 6. Experimental models.

tion of the channel, the incident and reflected wave amplitudes, denoted by $H_{\imath}$ and $H_{r}$, respectively, are obtained from the expressions

$$
\begin{aligned}
& H_{i}=\frac{\left|\eta_{1}+\eta_{2}\right|_{\max }+\left|\eta_{1}+\eta_{2}\right|_{\min }}{2} \\
& H_{r}=\frac{\left|\eta_{1}+\eta_{2}\right|_{\max }-\left|\eta_{1}+\eta_{2}\right|_{\min }}{2}
\end{aligned}
$$

Limitations of experimental facility. The train of waves was assumed to travel from $-\infty$ to $\infty$, even though it originated at about -5.6 meters and broke on the beach at about +5.6 meters, taking the origin to be at the center line of the useful experimental section of the channel. Because of the small inertia of the sheet, it was necessary to restrain it from drifting in the channel. In test 10 , however, the drift was only about 0.61 meter in $20 \mathrm{~min}$. The steeper waves overran the edge of the sheet to some extent. In addition, there was water leakage through the clearance between the longi-

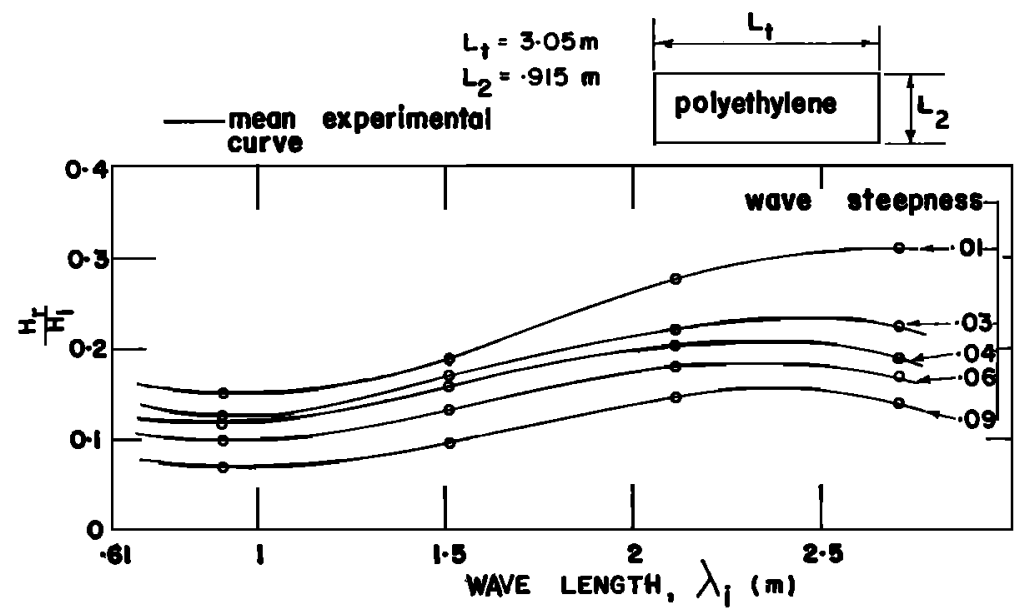

Fig. 7. Wave reflection. 


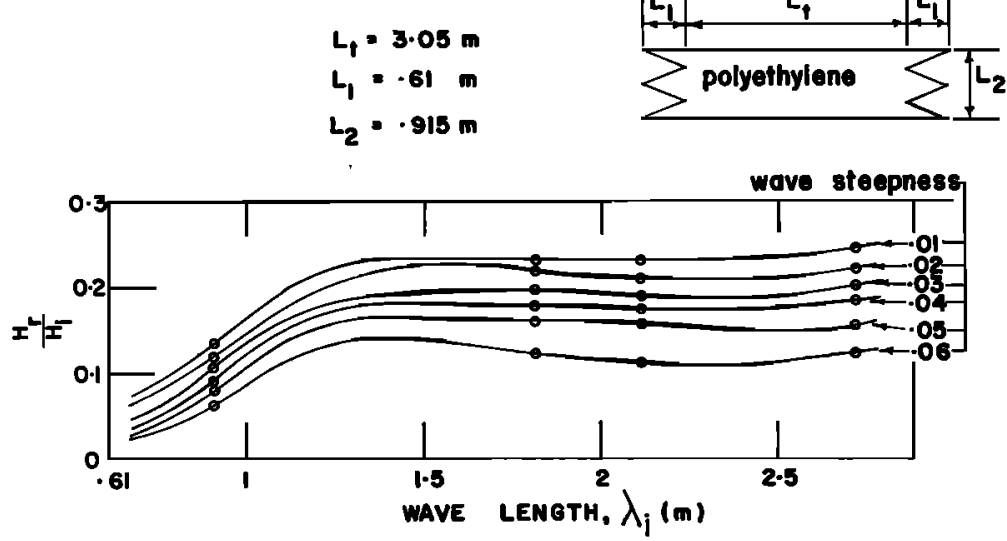

Fig. 8. Wave reflection.

tudinal edge of the sheet and the glass walls of the channel. The removal of overtopping water was accomplished with reasonable success before the measurements of the wave form in the channel were taken. For the shorter waves, an almost uniform layer of water varying from about 0.16 to $1.5 \mathrm{~cm}$ deep overtopped the sheet. Attempts to eliminate this water did not succeed, since it took only a few seconds for the layer to accumulate. In test 10 for the unrestrained sheet the overtopping water made the sheet unstable, and, once the instability began, the magnitude of the submersion continued to increase.

\section{Discussion of Results}

From tests 3 to 6 plots are shown of $H_{r} / H_{4}$ and $H_{t} / H_{t}$ against $\lambda_{t}$ for wave steepnesses varying from 0.01 to 0.1 in Figures $7,8,9$, and $10 ; H_{r} / H_{\text {، }}$ against $\lambda_{\text {، }}$ for a constant wave steepness of 0.05 is shown in Figure $11 ; a / a_{0}$ against distance $x$ from leading edge of sheet is indicated in Figure $12 ; E_{4} / E_{1}$ against $\lambda_{4}$ is shown in Figure 13.

Comparison of experimental results with theory. For the mathematical models used in this section, reference is made to the theoretical prediction of reflection coefficient by Shapiro and Simpson [1953] for the reflection by a broken ice field, as indicated in Figure 14, and then to the work of Hendrickson et al. [1962] and Hendrickson and Webb [1963] for the reflection from an ice floe, as shown in Figure 15. From the laboratory model a mean reflection coefficient may be defined over the range of wavelengths covered by the experiment. The trend of the results shown in Figure 11 differs from the trend exhibited in Figure 14 and can

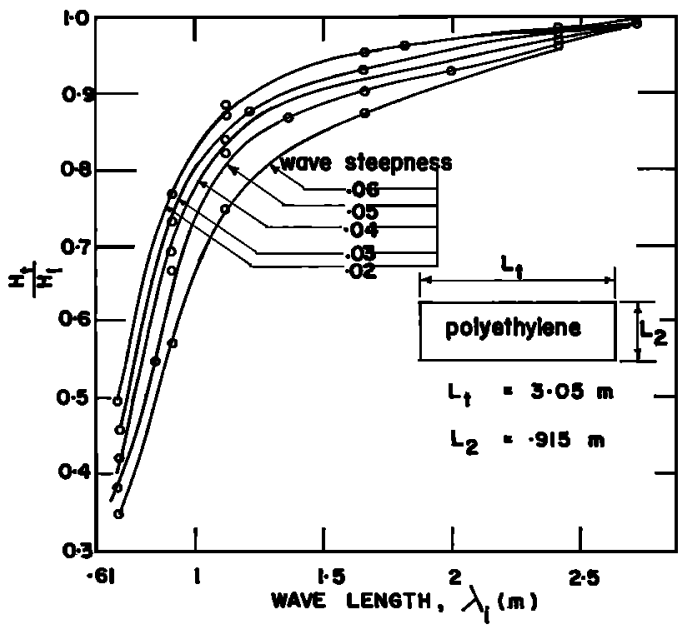

Fig. 9. Wave transmission.

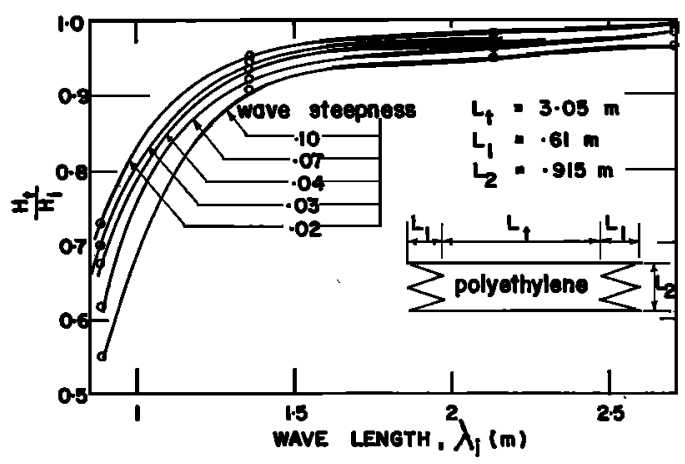

Fig. 10. Wave transmission. 


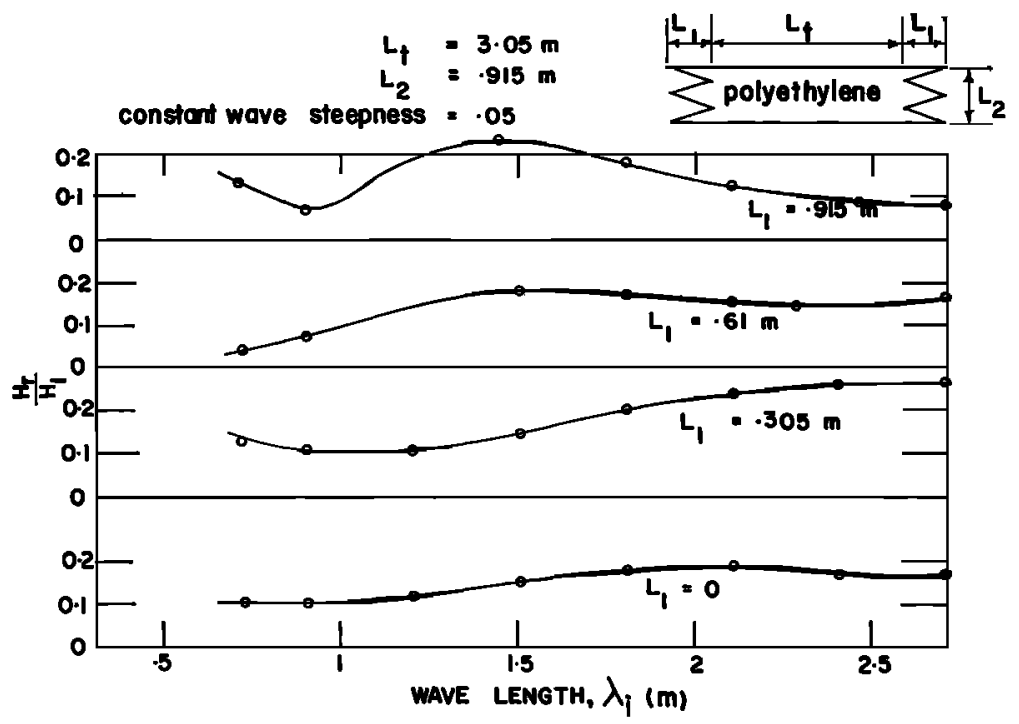

Fig. 11. Wave reflection at a constant wave steepness.

be attributed to the basic differences between the experimental and theoretical models. From the analysis on reflection and transmission, it is evident that different parameters influence wave reflection from, and transmission through, a

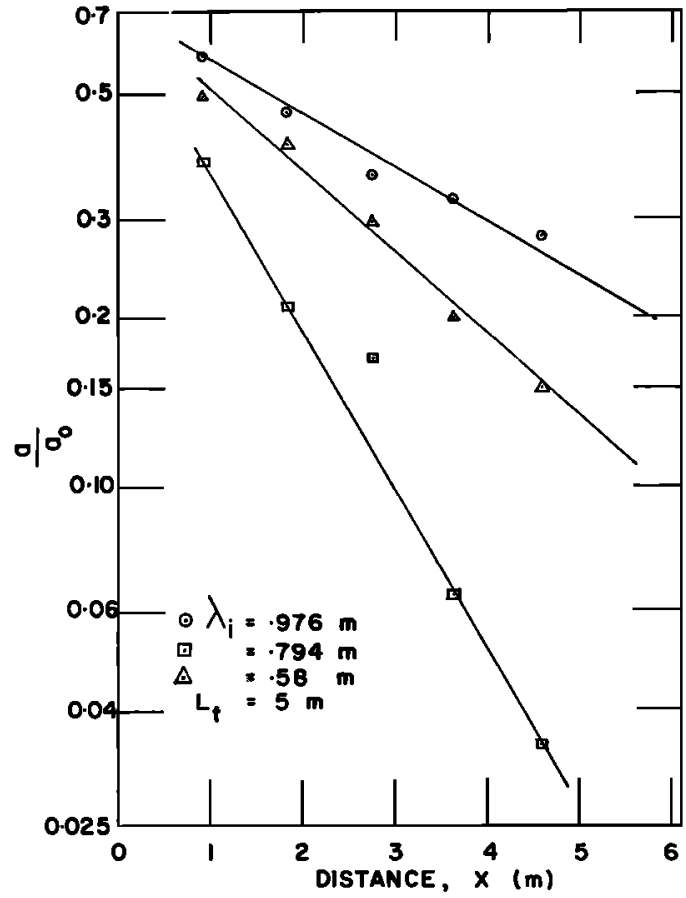

Fig. 12. Wave attenuation. broken ice field compared with that of an unbroken ice field.

A comparison of the experimental results with the theory, shown in Figure 15, is made by using the values for the laboratory model and for the mathematical model ice floe. Table 3 shows the magnitudes of certain dimensionless parameters and the reflection coefficients obtained for both models, for given values of $b / \lambda_{\text {, }}$ and $E b^{\mathrm{a}} / \rho_{\mathrm{w}} g \lambda_{i}{ }^{4}$. Each of the parameters

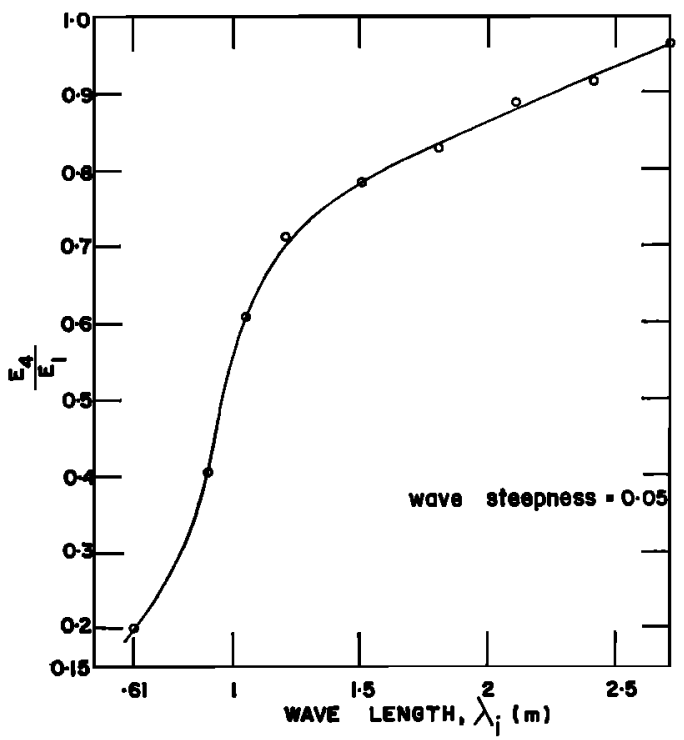

Fig. 13. Energy dissipation. 


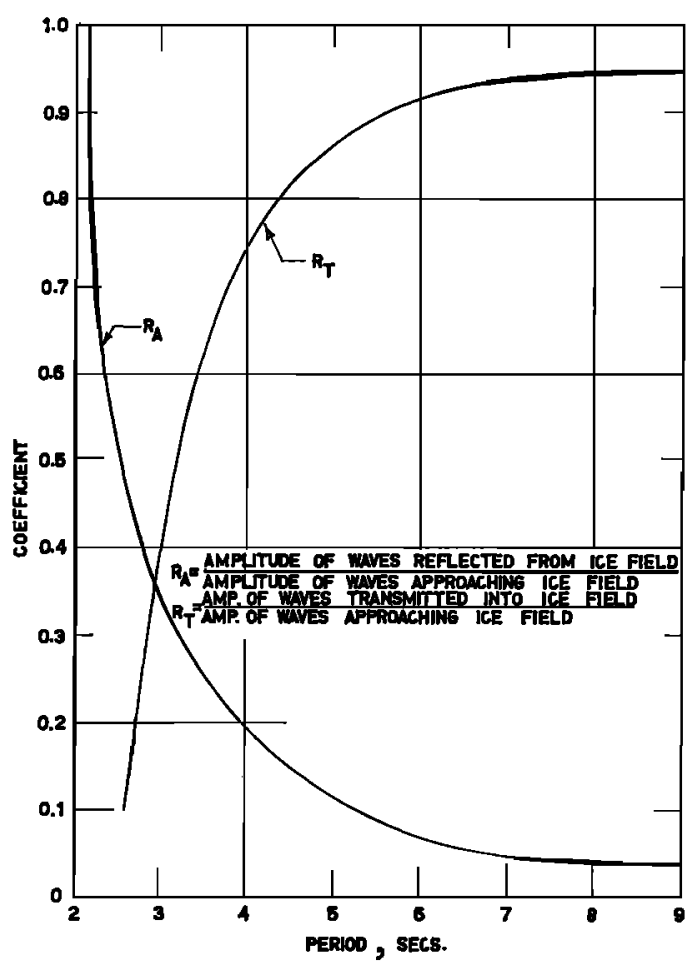

Fig. 14. Broken ice field: wave reflection and transmission [after Shapiro and Simpson, 1953].

$E b^{2} / \rho_{w} g \lambda_{i}{ }^{4}, b / H_{4}$, and $b / \lambda_{4}$ appears to contribute significantly to wave reflection. Figure 16, a plot of the transmission coefficient as a function of the lengths of indentation of the leading and trailing edges and $\lambda_{t}$, is drawn to determine whether or not the system exhibits an optimum edge condition for wave transmission. Since processes within the sheet and at the leading and trailing edge discontinuities account for all the energy dissipation, a measure of the reflection coefficient only is insufficient to determine the optimum condition for wave propagation. In Figure 16 a peak is exhibited in the neighborhood of $L_{1} / \lambda_{1}=1 / 3$. Therefore, that configuration of the leading and trailing edges may be interpreted as being the most efficient in transmitting wave energy under the experimental conditions.

It may be noted in reference to Figures 7, 8, 9 , and 10 that the transmission and reflection of water waves are not simply related. This phenomenon may be attributed to energy dissipation which is augmented by increase in the effective lengths of the leading and trailing boundaries. In test 3 and for incident wavelengths of 1.53 meters and greater, about $80 \%$ of the incident wave energy is recovered at the trailing edge of the sheet. There is a remarkable decrease of about $50 \%$ in the amount of energy transmitted between wavelengths of 1.22 and 0.61 meter. Since the reflected wave energy accounts for less than $5 \%$ of the incident wave energy, other mechanisms occurring under, within, and over the sheet and at the boundaries of the sheet may contribute significantly to wave energy dissipation.

In test 7 , it is found that waves of great length were hardly attenuated in passing through

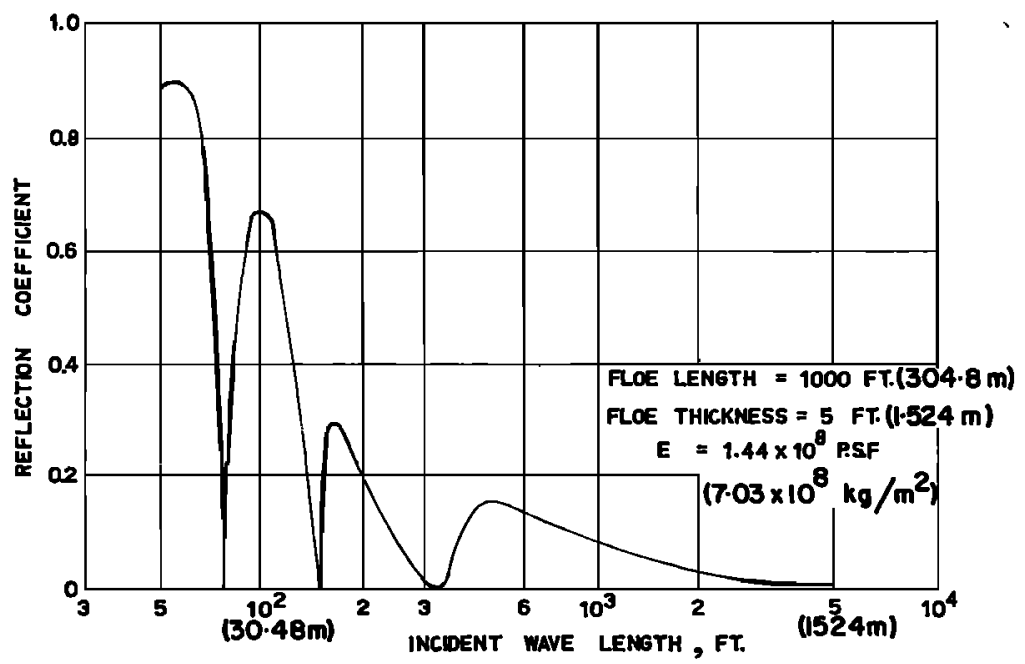

Fig. 15. Response of ice floe to incident waves [after Hendrickson et al., 1962]. 
TABLE 3

$E, \mathrm{~kg} / \mathrm{m}^{2} \quad b$, meters $\quad \begin{gathered}\lambda_{i}, \\ \text { meters }\end{gathered} \quad b / \lambda_{i} \quad \frac{E b^{3}}{p_{w 0} g \lambda_{i}{ }^{4}} \quad H_{i} / \lambda_{i} \quad b / H_{i} \quad H_{r} / H_{i}$

Mathematical model ice flos

$7.03 \times 10^{8}$

Laboratory model

Mathematical model

ice floe

$1.54 \times 10^{8}$

1.523

763

0.002

$7.4 \times 10^{-6}$

$\rightarrow 0$

1

$1.62 \times 10^{-3}$

0.05

0.04

0.02

$7.03 \times 10^{8}$

1.523

188.0

0.0081

0.002

$\rightarrow 0 \quad 1$

$1.54 \times 10^{8}$

0.00153

0.732

0.0021

0.002

$0.08 \quad 0.026$

0.14

0.08

the sheet. Standing waves were formed in the channel in the tests in which the size of the sheet was small compared with the lengths of the incident waves.

Some of the sources of energy loss tending to be augmented with decreasing wavelengths are discussed. The waves incident on the floating sheet consisted of several spectral components, and some energy dissipation occurred in the complex processes of energy interchange among the various components. The shorter waves tended to break at the discontinuity of the media at the leading boundary. Waves overran this edge to create an almost uniform layer of water overtopping the sheet. The quantity of water increased as the incident wavelength decreased. Thus, under these conditions, the system may be considered as a three-layer system in which the sheet was slightly submerged and the incident wave energy was propagated through the sheet, the water above, and the water below. When discontinuous pools of water were formed in tests 3 to 6 , the deflecting sheet created hydraulic jumps, which are major sources of energy drainage from a fluid system. Because wave propagation through the system is a process involving repeated bending of the material, a small fraction of the incident energy may be dissipated, owing to the effect of hysteresis.

Calculation of energy dissipation. The realistic calculation of the decay of wave energy in an ice field would be difficult. This difficulty arises from the fact that energy losses are caused by some processes whose contribution is mathematically difficult to consider. Since

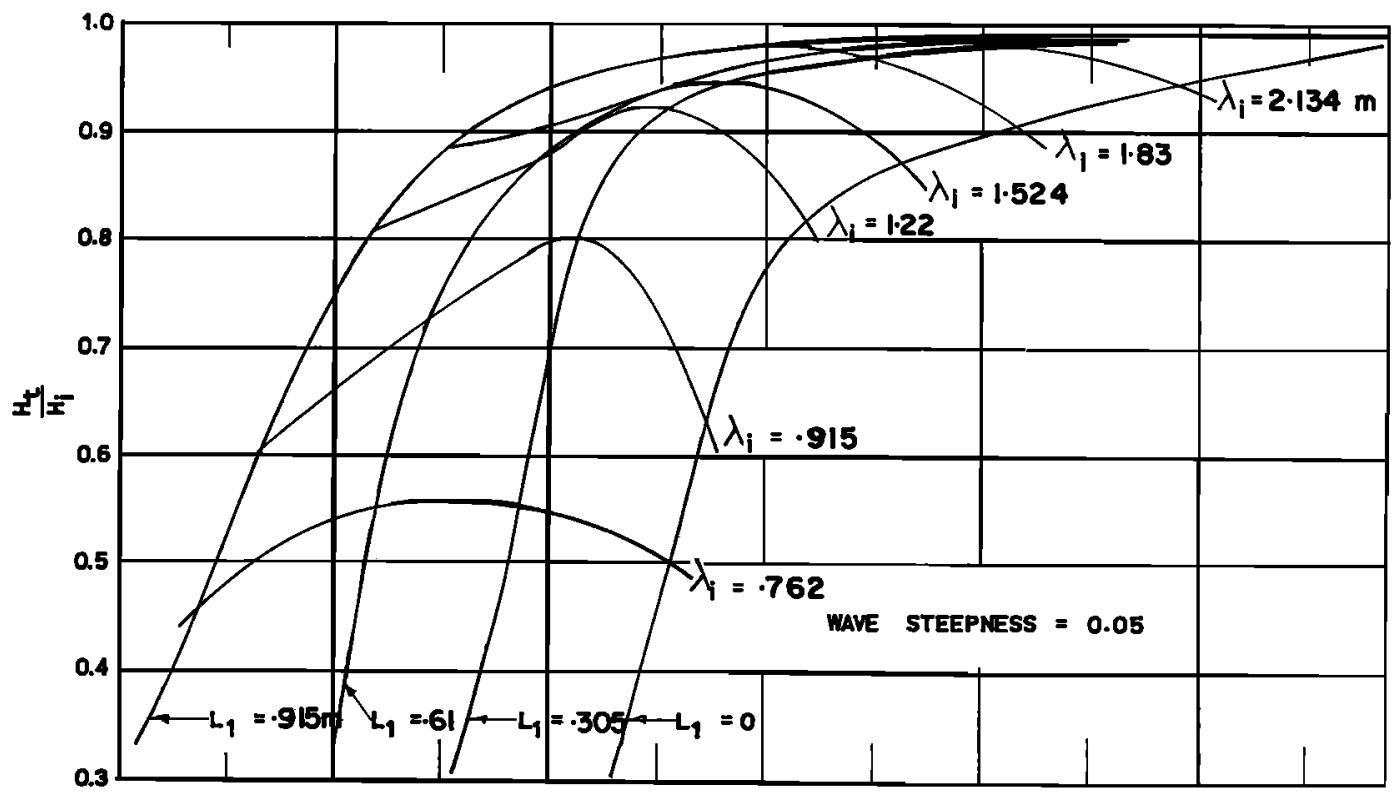

Fig. 16. Edge configurations and wave transmission. 
ice floes are usually characterized by irregular surfaces caused by varying environmental conditions during formation, the irregularity of surface and boundaries ought to be taken into account in energy consideration. Furthermore, for an ice field consisting of a number of floes, slushing of water between the floes and their edges may account for a considerable loss of energy.

Therefore, in the calculation of the energy loss, which can occur in an ice sheet, an ideal model is considered. In this model, the floe is assumed to be a smooth continuous plate in which energy dissipation does not occur within the plate and in the atmosphere above it. Thus, energy dissipation in the real ice field would be expected to exceed many times that predicted by use of an ideal model.

By considering the floating sheet as inextensible, the dissipation in an ideal case is found by considering the stream function representing the motion set up in a semi-infinite viscous liquid by a waving inextensible sheet [Reynolds, $1965 a$ ] and computing the average work per unit area of the wave field done by the shear stresses at the sheet.

It is found that the work done $W$ in maintaining the wave system is given (Appendix 1) by the following expression:

$$
W=\frac{\mu a^{2} k^{3} c^{2}}{2}\left(\frac{s \beta \sin \phi}{1+\beta^{2}-2 \beta \cos \phi}\right)
$$

to a first approximation and second order in parameter, where $\beta=\left(1+s^{2}\right)^{1 / 4} ; \tan 2 \phi=$ s; $0^{\circ}<\phi<45^{\circ}$; and Reynolds number, $s=$ $c / \gamma_{1} k$.

In the case of very slightly viscous fluid $s \rightarrow$ $\infty, \beta \rightarrow s^{1 / 2}$, and $\phi \rightarrow 45^{\circ}$

$$
W \rightarrow W_{1}=\frac{\mu a^{2} k^{3} c^{2}}{2}\left(\frac{s}{2}\right)^{1 / 2}
$$

The treatment given by Lamb [1932] to the problem of the effect of viscosity on free oscillatory waves gives results similar to expression 8 .

A comparison of the expression with Stokes' estimate of the energy dissipation in waves with a free surface is made. In Stokes' estimate the work done $W_{0}$ is given by

$$
W_{0}=2 \mu a^{2} k^{3} c^{2}
$$

hence,

$$
W_{1} / W_{0}=s^{1 / 2} / 4 \sqrt{2}
$$

This result shows that at high Reynolds number, $s$, the dissipation under an inextensible floating sheet is much greater than that in the absence of restraint in the surface. This fact may be attributed to the very high shear in the thin boundary layer on the lower surface of the plate. Furthermore, the rate of decay of the wave system in the absence of energy input is obtained by equating the dissipation to the rate of change of total wave energy. In the models of Reynolds [1963] of an infinitely flexible sheet covering the surface of the water and of Lamb [1932] for the case of the calming effect of an oil film on water waves, it is found that the rate of wave amplitude decay is given by

$$
\begin{gathered}
\frac{a}{a_{0}}=\exp \left(-\frac{\gamma_{w} k^{2}}{2}\left(\frac{s}{2}\right)^{1 / 2} t\right) \\
a / a_{0}=e^{-x / L_{0}}
\end{gathered}
$$

Expression 11 also predicts the mode of wave amplitude decay in wave transmission through a floating massive elastic plate. The time constant of decay is, however, increased above the oil film value owing to the presence of the plate. The length scales of wave-amplitude decay $L_{p}$, defined as the distance over which the wave amplitude decreases to $1 / e=37 \%$, are obtained in the laboratory model for wavelengths of $0.58,0.793$, and 0.976 meter by applying the experimental results shown in Table 4 and the expression

$$
a / a_{0}=e^{-x / L_{3}}
$$

These results are compared with the length scales of decay resulting from the wave damping effect of an oil film. Figure 12 shows a plot of $\left(a / a_{0}\right)$ against distance. Table 5 shows a comparison of the length scales of decay for the sheet and an oil film. A large difference in the wave damping characteristics of the sheet and an oil film is exhibited, as anticipated. This fact suggests that the contribution to energy losses by mechanisms other than the high rate of shear existing at the interface of the water and the sheet are important. The effective viscosity for the damping produced by the sheet is about $25 \mu_{\mathrm{w}}$.

Energy balance. In Table 6 a detailed energy 
TABIE 4. Wave Attenuation

\begin{tabular}{ccccc}
\hline \multirow{2}{*}{$\begin{array}{c}\text { Distance from } \\
\text { Leading Edge, } \\
\text { meters }\end{array}$} & $\begin{array}{c}\text { Fractional } \\
\text { Distance from } \\
\text { Leading Edge }\end{array}$ & $\begin{array}{c}\lambda_{i}^{*}=0.976 \\
\text { meter }\end{array}$ & $\begin{array}{c}\lambda_{i}^{*}=0.793 \\
\text { meter }\end{array}$ & $\begin{array}{c}\lambda_{i}^{*}=0.58 \\
\text { meter }\end{array}$ \\
\cline { 3 - 5 } & 0.182 & 0.585 & 0.500 & 0.380 \\
0.915 & 0.364 & 0.470 & 0.410 & 0.220 \\
1.830 & 0.545 & 0.360 & 0.295 & 0.170 \\
2.74 & 0.725 & 0.330 & 0.205 & 0.065 \\
3.660 & 0.910 & 0.275 & 0.150 & 0.035 \\
4.57 & & & & \\
\hline
\end{tabular}

* Amplitude of incident waves.

balance is carried out for the wavelengths shown in Table 5 . In the detailed energy balance, the incident wave energy decomposes into the following elements, shown in Figure 17:

$L_{r}$, the energy of the reflected wave. 1-2.

$L_{12}$, the energy dissipated in the boundary

$L_{33}$, the energy dissipated in the sheet.

$E_{3}$, the wave energy incident on the boundary 3-4.

$L_{34}$, the energy dissipated at the rear edge $3-4$.

$E_{4}$, the transmitted wave energy.

The total energy

$$
T=L_{r}+L_{12}+L_{23}+L_{34}+E_{4}
$$

$L_{12}$ is assumed to be given by the expression

$$
L_{12}=(1-T) E_{1} /\left(1+E_{3}\right)
$$

$L_{2 \mathrm{~s}}$ and $L_{34}$ are obtained from the expression

$$
\begin{aligned}
& L_{23}=E_{1}-L_{r}-L_{12}-E_{3} \\
& L_{34}=E_{3}-E_{4}
\end{aligned}
$$

$E_{1}$ is considered to be equal to the square of the incident wave amplitude; that is, $E_{1}=a_{0}{ }^{2}$. Therefore, $E_{\text {a }}$ may be calculated by applying expression 13 , which gives

$$
E_{3}=\left(E_{1}-L_{12}-L_{r}\right) e^{-2 L_{1} / L_{p}}
$$

Table 6 emphasizes the fact that at the lower wavelengths a small fraction of the total incident wave energy is reflected, transmitted, and dissipated at the leading and trailing edges of the sheet. A large fraction of the incident wave energy is dissipated within the deflecting sheet.

In the analysis of the experimental observations reported by Robin [1963b] he adopts an arbitrary frequency of cutoff of wave transmission, defined as the frequency at which the spectral energy density falls below $500 \mathrm{~cm}^{2} \mathrm{sec}$. Robin finds that an approximately linear relationship exists between the diameter of ice floes, defined with respect to an equivalent number of wavelengths of the incident waves and the wavelengths at which the cutoff of wave transmission is experienced. Furthermore, cut-

\begin{tabular}{|c|c|c|c|c|c|}
\hline \multirow{2}{*}{$\begin{array}{l}\text { Wavelength } \\
\lambda_{i}, \text { meter }\end{array}$} & \multirow{2}{*}{$\begin{array}{c}\text { Wave } \\
\text { Steepness } \\
H_{i} / \lambda_{i}\end{array}$} & \multirow{2}{*}{$\begin{array}{l}\text { Reflection } \\
\text { Coefficient }\end{array}$} & \multicolumn{2}{|c|}{$\begin{array}{l}\text { Characteristic } \\
\text { Amplitude Decay } \\
\text { Length, meters }\end{array}$} & \multirow[b]{2}{*}{$L_{0} / L_{p}$} \\
\hline & & & $L_{p}$ & $L_{0}$ & \\
\hline 0.58 & 0.092 & 0.07 & 1.54 & 36.6 & 23.8 \\
\hline 0.793 & 0.096 & 0.075 & 2.80 & 61.0 & 21.8 \\
\hline 0.976 & 0.091 & 0.07 & 4.55 & 91.5 & 20.1 \\
\hline
\end{tabular}
off of wave transmission is found to occur when the wavelength is about 3 times the diameter of the ice floe, and the effect of wave attenuation

TABLE 5. Comparison of Decay Lengths 
TABLE 6. Energy Balance

\begin{tabular}{|c|c|c|c|c|c|c|c|c|c|}
\hline & $E_{1}$ & $L_{\text {r }}$ & $L_{12}$ & $L_{23}$ & $E_{3}$ & $L_{34}$ & $E_{\boldsymbol{t}}$ & $T$ & $\underset{\text { meters }}{L_{p,}}$ \\
\hline \multirow[t]{2}{*}{1} & $\begin{array}{l}1 \\
1\end{array}$ & $\begin{array}{l}0.0049 \\
0.0049\end{array}$ & $\begin{array}{c}0 \\
0.0004\end{array}$ & $\begin{array}{l}0.9937 \\
0.99331\end{array}$ & $\begin{array}{l}0.00139 \\
0.00139\end{array}$ & $\begin{array}{c}0 \\
0.00039\end{array}$ & $\begin{array}{l}0.001 \\
0.001\end{array}$ & $\begin{array}{l}0.9996 \\
1.000\end{array}$ & $\begin{array}{l}1.54 \\
1.54\end{array}$ \\
\hline & Balanced & & & & & & & & \\
\hline \multirow[t]{2}{*}{2} & 1 & 0.0056 & 0 & 0.9671 & 0.0273 & 0 & 0.015 & 0.9877 & 2.80 \\
\hline & $\begin{array}{c}\overline{1} \\
\text { Balanced }\end{array}$ & 0.0056 & 0.012 & 0.9554 & 0.0270 & 0.012 & 0.015 & 1.000 & 2.80 \\
\hline \multirow[t]{2}{*}{3} & 1 & 0.0049 & 0 & 0.8866 & 0.1085 & 0 & 0.02 & 0.9115 & 4.55 \\
\hline & $\begin{array}{c}1 \\
\text { Balanced }\end{array}$ & 0.0049 & 0.081 & 0.8141 & 0.100 & 0.080 & 0.02 & 1.000 & 4.55 \\
\hline
\end{tabular}

becomes appreciable when the wavelengths are about 6 times the size of the floe.

Expressions 3 and 4 indicate the dimensionless factors influencing wave transmission. Hence, model and prototype may not be related on the basis of $\lambda_{t} / L_{t}$ or $L / L_{t}$ only. For instance, the wavelengths used in the laboratory model vary from about $1 / 8$ to $11 / 2$ times the length of the sheet; that is $1 / 8 \leqq \lambda_{1} / L_{t} \leqq 3 / 2$. At the frequency of cutoff of wave transmission in Robin's report, however, the wavelengths of incident waves are about 3 times the diameter of the floes; that is, $\lambda_{t} / L_{t} \approx 3$.

It has been remarked that a large energy decrease is experienced by short incident waves. The rapid energy loss occurs within a narrow band of wavelengths. The theoretical model of Shapiro and Simpson [1953], Figure 14, also indicates that a rapid decrease in energy penetration is experienced over a small band of wave periods. However, Robin compares the results of observations with the prediction by Shapiro and Simpson and finds that a large discrepancy exists owing partly to the fact that the theoretical curves of Shapiro and Simpson are applicable to a continuous broken ice field rather than to a number of patches of pack ice.

Prediction of wave attenuation. In his ob-
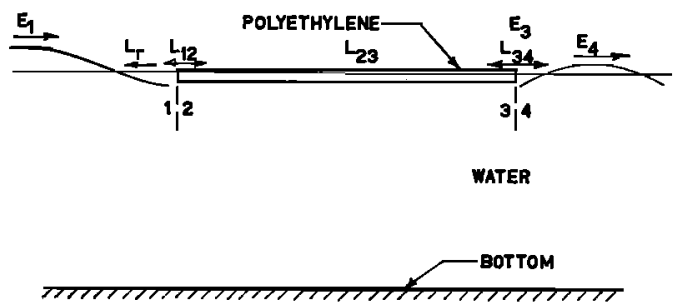

Fig. 17. Energy distribution. servations of the south polar seas, Robin [1963b] gives the measurements of the spectral energy density in the open sea (latitude $66.1^{\circ} \mathrm{S}, 66.9^{\circ} \mathrm{S}$ ) and in pack ice (latitude $67.4^{\circ} \mathrm{S}$ ). Because of the similarities of the shapes of the spectral energy density curves, it is assumed that steady conditions existed in pack ice, in the open sea, and at the edge of the pack during the intervals between measurements. Furthermore, it is assumed that a continuous pack covered the distance between the stations where wave measurements were made.

By assuming effective viscosities of $35 \mu_{w}$, $50 \mu_{w}$, and $70 \mu_{w}$ in the decay of open sea waves that pass into pack ice, the spectral energy density of waves propagating through about 35 miles of pack ice (latitude $66.9^{\circ} \mathrm{S}$ to latitude $67.4^{\circ} \mathrm{S}$ ) is calculated by means of expression 11 and is plotted in Figure 18, where values obtained from the spectral energy density curve $P_{1}$ are used in the calculation.

It is evident that in Robin's measurements an effective viscosity of about $50 \mu_{w}$ is applicable to the damping experienced by open sea waves passing into pack ice. Hence, within the limitations of the assumptions and on the basis of Robin's measurements, the damping experienced by waves passing into pack ice may be approximately predicted. The experimental results of the phase velocity through the floating sheet are shown in Figure 19. An analysis is performed to determine the effect of overtopping water on wave propagation through the sheet. Furthermore, an experiment was conducted to determine the changes in the effective modulus of elasticity of polyethylene with its frequency of straining.

Effect of water overtopping the sheet. The 


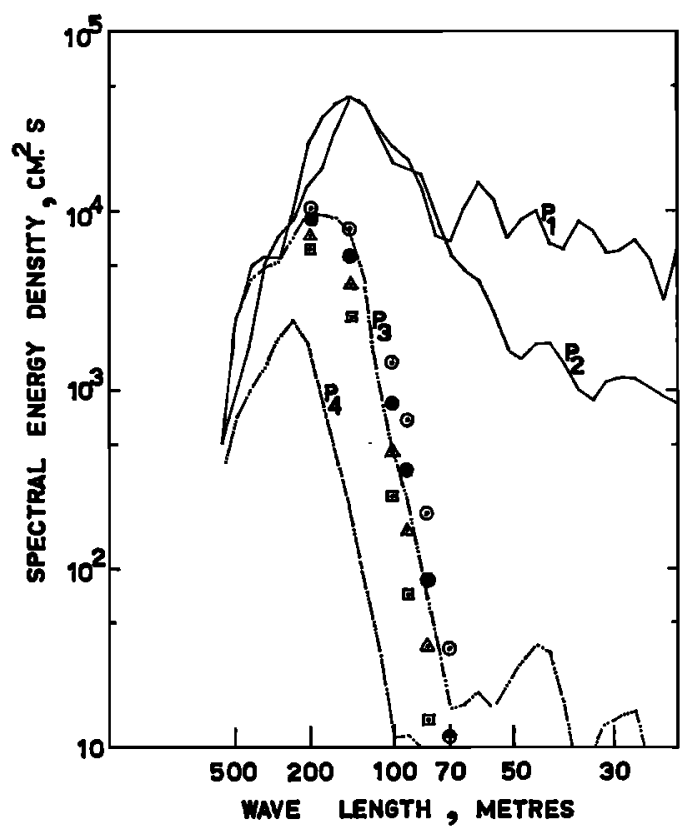

Fig. 18. Spectral energy density in open sea and in pack ice [after Robin, 1963]. $P_{1}, P_{2}$, latitude $66.1^{\circ} \mathrm{S}, 66.9^{\circ} \mathrm{S} ; P_{\mathrm{s}}$, latitude $67.4^{\circ} \mathrm{S}$; $P_{d_{1}}$ latitude $67.6^{\circ} \mathrm{S}$. Circles with dot: effective viscosity $35 \mu_{s}$ applied to $P_{1}$; solid circles: effective viscosity $50 \mu_{10}$ applied to $P_{1}$; triangles: effective viscosity $70 \mu_{\infty}$ applied to $P_{1}$; squares: effective viscosity $50 \mu_{\omega}$ applied to $P_{1}$ latitude $66.9^{\circ} \mathrm{S}$ to latitude $67.6^{\circ} \mathrm{S}$.

analysis for the submerged sheet is analogous to that given by Lamb [1932] for wave propagation at the interface of two superposed fluids. The main difference in the system lies in the fact that, in the case under consideration, wave propagation is a function of the elastic properties of the submerged plate. The system shown in Figure 20 is considered.

The velocity potentials describing the motion of the fluid above and below the sheet are expressed, in the frame of reference traveling with the crest, as

$$
\begin{gathered}
\Phi_{2}=-C x+\varphi_{2}=-C x \\
+(A \cosh k y+B \sinh k y) \cos k x \\
\Phi_{3}=-C x+\varphi_{3}=-C x \\
\quad+C_{2} \cosh k(y+h) \cos k x
\end{gathered}
$$

where $C_{2}, A$, and $B$ are constants to be determined by applying the boundary conditions [Reynolds, 1965b] requiring that the vertical component of velocity at the bottom be zero, the vertical velocity be continuous across the sheet, and at the free surface the pressure be constant. Since the pressure differential produced by $P_{\mathrm{a}}$ and $P_{2}$ is sufficient to deflect and accelerate the sheet, the equation of motion becomes

$$
P_{3}-P_{2}=\frac{E I}{1-\gamma^{2}} \frac{d^{4} \eta}{d x^{4}}+\rho_{s} b C^{2} \frac{d^{2} \eta}{d x^{2}}
$$

Equation 19 is similar to equation 1 without the gravity term. By applying Bernoulli's equation,

$$
P-\rho C \frac{\partial \Phi}{\partial x}+\rho g \eta=\text { constant }
$$

to the motion of the fluid above and below the sheet and substituting in equation 19 the dynamic condition to be satisfied by $\varphi_{2}$ and $\varphi_{3}$ is given by (Appendix 2)

$$
\rho_{w} C\left(\frac{\partial \varphi_{9}}{\partial x}\right)_{0}+\frac{E I}{C\left(1-\gamma^{2}\right)}\left(\frac{\partial^{4} \varphi_{3}}{\partial x^{3} \partial y}\right)_{0}
$$

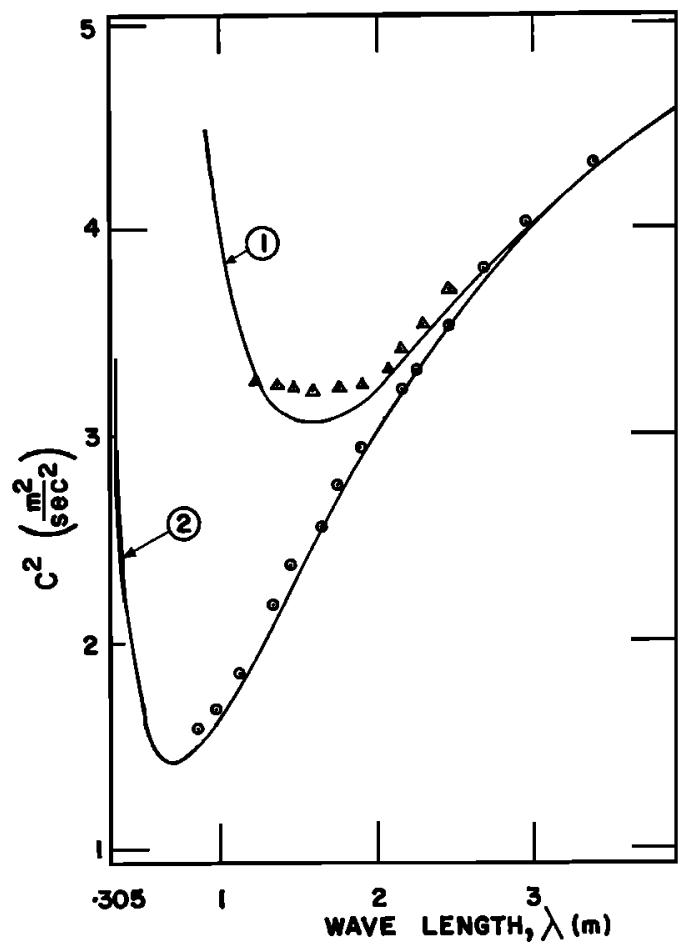

Fig. 19. Phase velocity in sheet. Curve 1 is theory at $b=0.465 \mathrm{~cm}$; triangles are exponents at $b=0.465 \mathrm{~cm}$. Curve 2 is theory at $b=0.156$ $\mathrm{cm}$; circles are exponents at $b=0.156 \mathrm{~cm}$. 


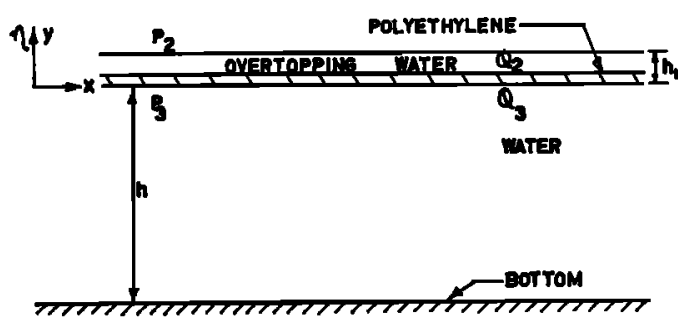

Fig. 20. Water overtopping the sheet.

$$
+\rho_{\mathrm{s}} b C\left(\frac{\partial^{2} \varphi_{3}}{\partial x \partial y}\right)_{0}=\rho_{w} C\left(\frac{\partial \varphi_{2}}{\partial x}\right)_{b}
$$

Furthermore, the phase velocity of waves in the sheet is found to be given by the expression

$$
\frac{\tanh k h_{1}-G}{1-G \tanh k h_{1}}=\frac{1-F \tanh k b}{\tanh k b-F}
$$

where

$$
\begin{gathered}
G=C^{2} k / g \\
F=-\frac{E I}{1-\gamma^{2}} \frac{k^{3}}{\rho_{w} C^{2}}+\frac{\rho_{s}}{\rho_{w}} b k+\operatorname{coth} k h
\end{gathered}
$$

The relationship expressed in equation 22 is

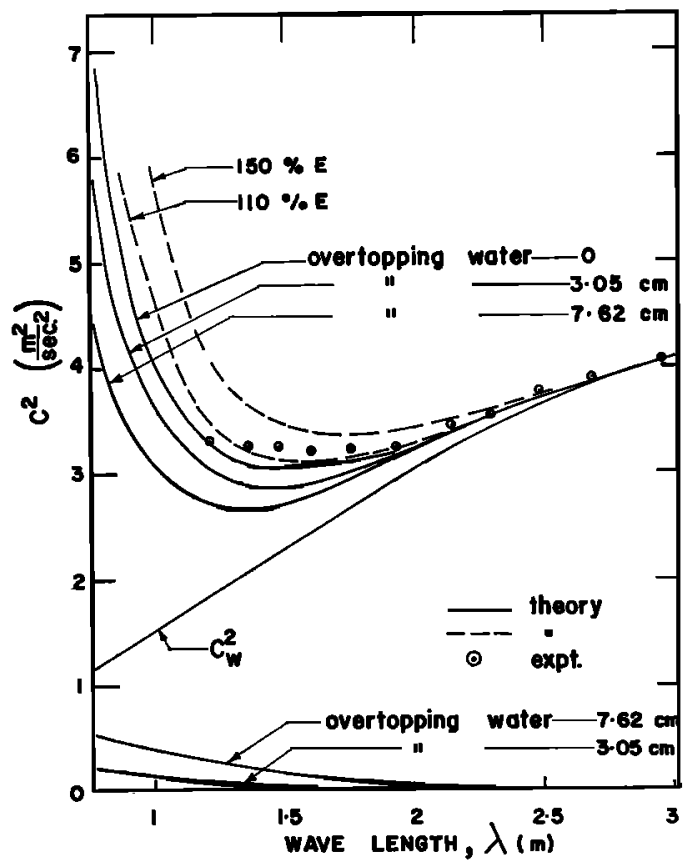

Fig. 21. Phase velocity, the effect of overtopping water and increase in the modulus of polyethylene. a quadratic in $C^{2}$, shown graphically in Figure 21. For a specific value of $h_{1}$, there are two celerities for any one wavelength; furthermore, for one frequency there are two wavelengths. The two solutions are considered associated with distinct modes of motion of the sheet and fluid medium, as shown in Figure 22 which shows the surface and sheet modes of wave motion.

In the experiment conducted to ascertain whether there is a significant variation of the effective dynamic modulus in the range of frequencies used in the laboratory model study, a plot of the effective modulus versus the frequency of oscillation was obtained. A mean slope of about $1.62 \times 10^{3} \mathrm{~kg} / \mathrm{cm}^{2} / \mathrm{cps}$ was obtained. Therefore, the assumption of a constancy of the effective modulus of polyethylene under dynamic conditions requires some modification.

\section{Conclusions}

Results from the simple model appear to indicate the feasibility of a laboratory model study of the dynamic behavior of the complex natural system of pack ice and ocean waves.

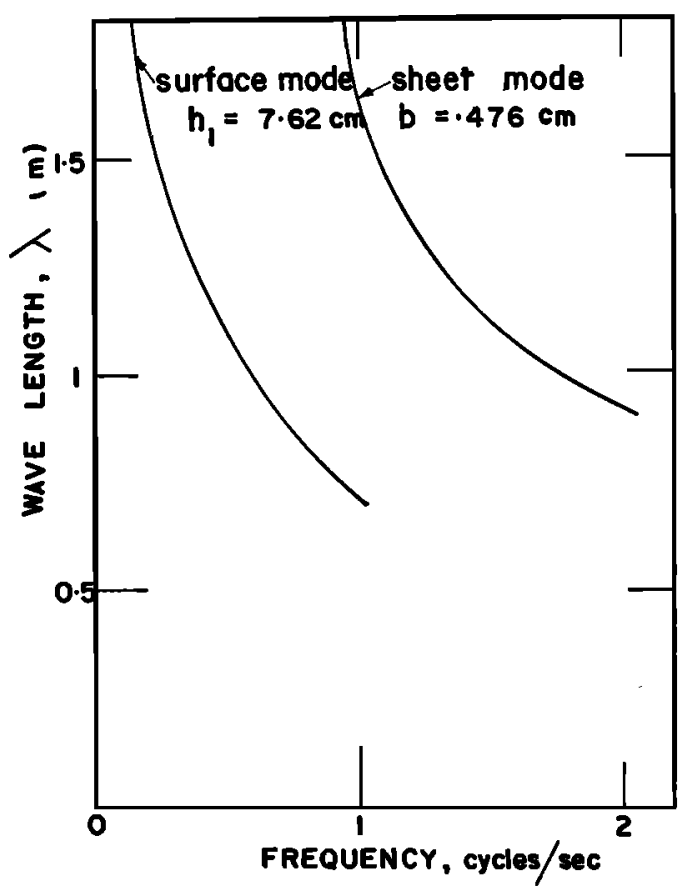

Fig. 22. Surface and sheet modes of wave motion. 
A simple relationship does not appear to exist between the wave reflected from the sheet and the wave transmitted through the system. Optimum wave acceptance by the sheet is obtained when the length of cut of its leading and trailing edges compared with the wavelength of the incident waves is about one-third.

The amplitude of the wave train reflected by the sheet is generally about $10-20 \%$ of the incident wave amplitude for a wave steepness of 0.05 . The unsubmerged fraction of the sheet, the ratio of sheet thickness to incident wave height, and the ratio of the elastic wave energy in the sheet to the gravitational wave energy of the incident wave contribute significantly to wave reflection.

There is selective damping of the incident waves. Long waves pass through the sheet with little loss of energy. Waves of short lengths, however, experience immense attenuation resulting from energy losses due to hysteresis in the deflecting sheet, energy dissipation in the boundary layer beneath the sheet, and energy loss in the hydraulic jumps formed by overtopping water during wave motion.

The amplitude decay of waves in the thin sheet is found to be approximately exponential for ratios of wavelength to length of sheet less than 1/5. The effective viscosity of the system is approximately $25 \mu_{\text {. }}$.

On the basis of measurements in the open sea and in pack ice, wave damping by pack ice of similar characteristics to those observed by Robin may be approximated by the wave damping of a liquid whose viscosity is about $50 \mu_{w}$, provided that the size of the pack ice is several times greater than the incident wavelength.

Reasonable agreement exists between experimental results and theoretical prediction of phase velocity for long waves. For short waves, however, systematically higher phase velocities are obtained. The increase in phase velocity is due partly to the increase in the effective dynamic modulus of polyethylene with its frequency of straining.

\section{APPENDIX 1}

The stream function representing the motion set up in a semi-infinite $(y>0)$ liquid by a waving inextensible sheet is [Reynolds, 1965a]

$$
=\frac{C a}{1+\beta^{2}-2 \beta \cos \phi}\left\{-\beta e^{-k y}[\sin (k x+\phi)\right.
$$

$$
\begin{aligned}
& -\beta \sin k x]+e^{-\beta k y c o s \phi}[\sin (k x-k \beta y \sin \phi) \\
& -\beta \sin (k x-\beta k y \sin \phi-\phi)]\}
\end{aligned}
$$

where

$$
\begin{aligned}
\beta & =\left(1+s^{2}\right)^{1 / 4} \\
s & =\sigma / \gamma k^{2}=c / \gamma k \\
\tan 2 \phi & =s \\
0^{\circ} & <\phi<45^{\circ}
\end{aligned}
$$

To the second order, the average work per unit area of the wave field done by the shear stresses at the sheet is

$$
W=-\mu C\left(\frac{\langle\partial u\rangle}{\partial y}\right)_{\eta}=\mu C\left(\frac{\left\langle\partial^{2} \psi\right\rangle}{\partial y^{2}}\right)_{\eta}
$$

where $u=-\partial \psi / \partial y$, and $v=\partial \psi / \partial x$ and where $\partial u / \partial y$ is to be evaluated on the sheet, given here by $\eta=a \sin k x$ and averaged over a wavelength. Now

$$
\begin{gathered}
\frac{\partial^{2} \psi}{\partial y^{2}}=\frac{C a \beta k^{2}}{1+\beta^{2}-2 \beta \cos \phi}\left\{-e^{-k y}[\sin (k x+\phi)\right. \\
-\beta \sin k x]+\beta e^{-\beta_{1} y}\left[\sin \left(k x-C_{1} y+2 \phi\right)\right. \\
\left.\left.-\beta \sin \left(k x-C_{1} y+\phi\right)\right]\right\}
\end{gathered}
$$

where $\beta_{1}=\beta k \cos \phi$ and $C_{1}=\beta k \sin \phi$.

Since the wave amplitudes are small, the following approximations can be made

$$
\begin{array}{r}
e^{-\beta_{1} \eta} \simeq 1-\beta_{1} \eta=1-\beta_{1} a \sin k x \\
\sin C_{1} \eta \bumpeq C_{1} \eta=C_{1} a \sin k x
\end{array}
$$

The only integrals to be evaluated are of the form

$$
\frac{1}{\lambda} \int_{0}^{\lambda} \sin ^{2} k x d x=\frac{1}{2}
$$

Hence, to the second order in $a k$, the work done is

$$
W=\frac{\mu a^{2} k^{3} c^{2}}{2}\left(\frac{s \beta \sin \phi}{1+\beta^{2}-2 \beta \cos \phi}\right)
$$

\section{APPENDIX 2}

The kinematic conditions to be satisfied by $\varphi_{2}$ and $\varphi_{3}$ are

$$
\frac{\partial \varphi_{3}}{\partial y}=0 \quad \text { at } \quad y=-h
$$




$$
\begin{aligned}
& \frac{\partial \varphi_{2}}{\partial y}=-C \frac{\partial \eta_{2}}{\partial x} \quad \text { at } \quad y=h_{1} \\
& \frac{\partial \varphi_{3}}{\partial y}=-C \frac{\partial \eta_{3}}{\partial x} \quad \text { at } \quad y=0
\end{aligned}
$$

where $\eta_{3}$ and $\eta_{2}$ are the sheet and surface deflections, respectively. At the free surface we have approximately

$$
\left(\frac{\partial \varphi_{2}}{\partial y}\right)_{y=b}=\left(\frac{\partial \varphi_{3}}{\partial y}\right)_{y=0}
$$

Condition A5 requires that the vertical velocity be continuous across the sheet. The dynamic conditions are

$$
C^{2} \frac{\partial^{2} \varphi_{3}}{\partial x^{2}}+g \frac{\partial \varphi_{3}}{\partial y}=0 \quad \text { at } \quad y=h_{1}
$$

and Bernoulli's equations are

$$
\begin{aligned}
& \text { on } y=0 \\
& P_{2}-\rho_{w} C \frac{\partial \varphi_{2}}{\partial x}+\rho_{w} g \eta=\text { constant } \\
& \text { on } y=b \\
& P_{\mathbf{a}}-\rho_{w} C \frac{\partial \varphi_{3}}{\partial x}+\rho_{w} g \eta=\text { constant }
\end{aligned}
$$

By introducing equations $\mathrm{A} 4, \mathrm{A5}, \mathrm{A6}$, and $\mathrm{A} 7$ into equation 19 one obtains equation 21. Also by introducing the velocity potentials $\varphi_{2}$ and $\varphi_{3}$ (equations $18 a$ and $18 b$ ) into equations A5, A6, and 19 and eliminating the constants $A, B$, and $C_{2}$, one gets equation 22 .

Acknowledgment. This work was supported by the Defence Research Board of Canada under grant 9511-60.

\section{Referiences}

Hendrickson, J. A., and L. M. Webb, Theoretical Investigation of Semi-Infinite Ice Floes in Water of Infinite Depth, National Engineering Science Co., Pasadena, California, June 1963.

Hendrickson, J. A., L. M. Webb, and R. J. Quigley, Study of Natural Forces Acting on Floating Ice Fields, National Engineering Science Co., Pasadena, California, September 1962.

Hunkins, Kenneth, Waves on the arctic ocean, J. Geophys. Res., 67 (6), 2477-2489, 1962.

John, F., On the motion of floating bodies, 1, Commun. Pure Appl. Math., 2(1), 13-57, 1949.

Lamb, H., Hydrodymamics, 6th edition, Dover Publications, New York, 1932.

Le Schack, L. A., On the generation and directional recording of waves in the Arctic Ocean, U.S. Naval Oceanographic Office Rept. TR-179, Sept. 1965.

Oliver, J., A. P. Crary, and R. Cotell, Elastic waves in arctic pack ice, Trans. Am. Geophys. Union, 35(2), 282-292, 1954.

Reynolds, A. J., Waves in pack ice, Fluid $M e-$ chanics Notes 1 and 2 , Department of Civil Engineering and Applied Mechanics, McGill University, June 1963.

Reynolds, A. J., The swimming of minute organisms, J. Fluid Mech., 23, 241-260, $1965 a$.

Reynolds, A. J., Effect of waves overtopping ice sheet, Fluid Mechanics Note 7, Department of Civil Engineering and Applied Mechanics, McGill University, July $1965 b$.

Robin, G. de Q., Ocean waves and pack ice, Polar Record, 11, 389-393, 1963a.

Robin, G. de Q., Wave propagation through fields of pack ice, Phil. Trans. Roy. Soc. London, 313-339, February $1963 b$.

Shapiro, A., and L. S. Simpson, The effect of a broken ice field on water waves, Trans. Am. Geophys. Union, $34(2), 36-42,1953$.

Weitz, M., and J. B. Keller, Reflection and transmission coefficients for waves entering or leaving an ice field, Commun. Pure Appl. Math., 6(3), 415-417, August 1953.

(Received August 5, 1966; revised March 2, 1967.) 